\title{
Aortic valve allografts in sheep
}

\author{
JOHN BORRIEAND G. L. HILL \\ From the Department of Surgery, University of Otago Medical School, Dunedin, New Zealand
}

\begin{abstract}
Some of the mechanical and biological problems surrounding the use of fresh allograft inverted aortic valves as mitral valve substitutes are described. Certain aspects of the problem have been studied experimentally. In three sheep 'fresh' aortic valve allografts were inserted, using cardiopulmonary bypass, into the main pulmonary artery, and were observed from 5 to 7 months after operation. The animals survived normally. Their normal pulmonary valves remained in situ. The technique is described. At subsequent necropsy, macroscopically the valves were found to be free from vegetation, and the cusps were pliable and apparently normal. Microscopically, the supporting allograft myocardium showed necrosis and early calcification. The valve cusp showed hyalinization of collagen, although beneath the endocardium this hyalinized collagen contained moderate numbers of fibroblasts with no evidence of proliferation. The endocardium and arterial intima of the allograft showed evidence of ingrowth from adjacent normal host endocardial tissues. The allograft itself was invested in a loose layer of fibro-fatty tissue, which, in view of the necrotic state of the graft myocardium, could well have been a reparative reaction rather than a homograft reaction. It is concluded that, although the cusps could function normally, the necrosis of the myocardium might in time lead to late failure of the graft. Further studies with the valve inserted at mitral level are indicated.
\end{abstract}

In earlier communications Borrie and Mitchell (1960) described the use of the sheep in surgical research, and later indicated that it was useful for studying mitral allograft (homograft) valves implanted under conditions of total pulmonary bypass (Borrie, Lichter, and Miller, 1967).

These studies on the mitral valve performed in 1966 and tabulated in the second paper had shown that an inverted, fresh allograft aortic valve, inserted via a left thoracotomy and atriotomy, with the animal placed on cardiopulmonary bypass and moderate hypothermia, could readily be implanted at the site of an excised mitral valve.

Two techniques for implanting had been used. In the first, the coronary artery ostia of the graft were opened to give three long strips of aortic wall and a broad valvular face presenting towards the left ventricle of the host. These long ends of aortic wall were sutured to the left ventricular wall at the site of the divided papillary muscles. The base of the inverted valve was attached by continuous suturing, reinforced by locking interrupted sutures, to the mitral annulus. In the second technique the coronary artery ostia of the graft were closed by purse-string sutures, and the valve was attached below to the mitral annulus and above to the left atrial wall.
During the attachment of the allograft valve to the base of the host's anterior mitral leaflet the $\frac{3}{3}$ aorta was temporarily cross-clamped, for we had tested experimentally that the sheep heart willof regularly tolerate cardiac anoxia from aortic cross-clamping for 30 minutes at $32^{\circ} \mathrm{C}$. witho subsequent complete recovery of the heart and $\underset{x}{0}$ normal survival of the animal.

In the mitral valve replacement experiments, however, since the normally functioning sheepo $\mathrm{A}-\mathrm{V}$ valve ring was considerably wider than the lumen of the implanted and inverted aortic valve, there was post-operative haemodynamic difficulty presumed to be due to 'mitral valve distortion' and을. regurgitation which caused the animals to succumb within 3 hours of operation from con-? gestive right heart failure.

THE PROBLEM

To be successful, the implanted aortic valve would first have to be sutured to a firm ring such as a Teflon ring, or a Teflon-coated stainless steel ring, and this firm ring could then be sutured into the्षे heart at the site of the A-V junction in the same way as the ring holding a Starr-Edwards ball-valve@ prosthesis is inserted. Thereafter, despite the 
muscular activity of the $\mathrm{A}-\mathrm{V}$ ring during each cardiac cycle, the implanted valve-fixed to a resilient ring-would not be unnecessarily deformed by the muscle changes and stresses of the cardiac cycle, nor by this means would it be rendered incompetent. Heimbecker (1961) had briefly mentioned this principle of a ring support when testing allograft valves at tricuspid level.

Before putting this idea into experimental practice at mitral level an aortic valve-complete with encompassing aortic wall and associated myocardium - would have to be tested to see whether it could be transplanted complete as a free allograft. Murray (1956) had reported the successful transplant of aortic allograft to the descending aorta in dogs, and briefly recorded success in three patients with aortic regurgitation, work confirmed by Beall, Morris, Cooley, and De Bakey (1961).

In clinical practice, Ross (1964) and BarrattBoyes (1964) have shown that aortic valves can successfully be implanted as allografts into the host aorta at the normal aortic valve site. But in such operations the valve has been carefully sutured on to the existing dilated aortic wall of the host. The implanted valve was thus supported on the outside in its new position by host aortic wall.

Where the aortic valve is to be used as an allograft to replace a mitral valve-and above all is to be attached to a fabric-coated ring-no such helpful natural support of this graft is possible. Further, no matter how careful the trimming, such a valve transplant still contains a sizable portion of heart muscle supporting its non-coronary cusp. We therefore decided to test the reliability of free aortic valve grafts of sheep experimentally, before returning to the main problem of inverting and inserting them at mitral level attached to inert rings. We were not aware at that time of other experimental work in which this particular facet of the problem had been thus tested. Nor have we encountered other work in which the sheep has been used as the experimental animal under bypass conditions. Further, as the sheep heart approximates the human heart in size, it offers a more interesting comparison with the human heart than does the dog heart. It also gives the opportunity for more detailed histological study of the phenomenon of graft acceptance or rejection, which has until now received scant study other than by McKenzie, Titus, Rastelli, Pappas, and Ellis (1966) and Hubka, Siška, and Holec (1967) in dogs and by Hudson (1966) and Smith (1967) in humans.

The purpose of this paper is to set out the problem, to describe the experimental technique used in testing aortic valve allografts in sheep, and to report the macroscopic and microscopic results obtained.

\section{THE EXPERIMENTAL MODEL}

What was required was a standard site where the problem of 'valve survival and acceptance as an unsupported unit' could be tested without the added problem of 'valve function in an abnormal site'.

It was therefore decided to implant allograft aortic valves into the main pulmonary artery as free grafts, and to check them for acceptance and survival six months after operation by macroscopic and microscopic study. The normal pulmonary valve cusps would be left intact. This would also allow one to check the valve cusps after transplantation, and to determine if the cardiac muscle supporting the coronary cusps of the homograft would in fact be accepted as satisfactorily as free grafts of aortic wall appeared to be accepted in humans. Would there be necrosis of the muscle, and would the muscle in time be replaced by fibrous connective tissue ?

No aortic valve allograft is completely devoid of cardiac muscle that supports at least one of its cusps. Further, the pressures in the pulmonary artery-rising to $30 \mathrm{~mm}$. $\mathbf{H g}$ - are not excessive and therefore need not cause rupture of the graft, as had occasionally occurred in sheep two months after fresh aortic allografts had been implanted into the descending thoracic aorta under conditions of left atrio-femoral artery partial bypass (Borrie, unpublished data).

PREPARATION OF THE VALVE The allograft valve for each experiment was obtained the day before operation from the heart of a sheep freshly slaughtered for the Dunedin Meat Market, and was purchased over the counter from a firm of butchers. A Starr-Edwards mitral valve in New Zealand (pre-devaluation) cost $\$ 200.00$, a Hammersmith mitral valve $\$ 50.00$, and a Dunedin valve 10 cents in this sheep-laden country.

The valve was dissected under clean but not sterile conditions, taking the tissue up to $0.5 \mathrm{~cm}$. proximal to the three aortic valve cusps centrally, and to $1 \mathrm{~cm}$. beyond the origin of the coronary arteries distally. Proximally, as much excess myocardial tissue as possible was dissected from the cusps as was excess of the anterior leaflet of the mitral valve. Distally, the two coronary artery ostia were closed with pursestring sutures. The valve preparation, after all excess tissue had been removed, was placed in nutrient medium with 500,000 units of penicillin and $0.5 \mathrm{~g}$. streptomycin and stored in a refrigerator. The test valve was thus prepared and placed in nutrient medium within eight hours of the donor animal having been slaughtered at the city abattoirs. Within two days the test valve was inserted into the test animal by the following technique. We did not attach a small cuff of aorta into the myocardial side of the valve to adapt this to the size of the proximal 
vessel, as described by Beall (1961) in studies on grafting aortic valves into the descending aorta.

METHOD OF INSERTION A Romney/Southdown wether, weighing $100 \mathrm{lb} .(45 \cdot 35 \mathrm{~kg}$.), was anaesthetized with nembutal, intubated, and maintained on gas oxygen and small doses of halothane.

With the animal lying on its back, its ventrum from neck to knee was cleansed with liquid soap and ether to remove lanolin, painted with Savlon solution, and draped with sterile towels.

The right femoral artery and veins were cannulated for continuous pressure recording on a Grass 4-channel recorder, and the three limb leads of the E.C.G. were attached, using needle electrodes. The left femoral artery was exposed for subsequent cannulation by the arterial line from the pump-oxygenator. The animal was then rolled on to its right-hand side, a standard fourth left intercostal space thoracotomy was performed, and the pericardial cavity was opened.

The sheep was then heparinized, the right atrial appendix was cannulated with a Bardic atrial catheter No. 34, the left femoral artery was cannulated with a Westminster cannula and then connected to an Ebsray pump-oxygenator with a 22-in. oxygenator in circuit, and primed with 1 litre of blood and 2 litres of Hartmann's solution. The blood, taken the day before-either by gravity from the external jugular vein or by femoral artery cut-down-was collected in bags containing $80 \mathrm{ml}$. of A.C.D. solution and $0 \cdot 3 \mathrm{ml}$. (1,500 units) of heparin solution. The perfusate was checked with an Astrup $p \mathrm{H}$ meter, and any acidity was countered with sodium bicarbonate solution.

The animal was placed on cardiopulmonary bypass by standard technique and cooled to $32^{\circ} \mathrm{C}$., during which time the main pulmonary artery was dissected throughout its whole length. The main pulmonary artery was doubly clamped, both at its origin and division, using Satinsky arterial clamps. The test valve was next sewn into position with No. 000 silk sutures, using for the posterior layer Blalock everting suture, and for the sides and front a continuous suture fre- quently locked to additional interrupted silk sutures. The distal anastomosis was completed first-and tested for leak by inflating the lungs and removing at the same time the distal clamps. The proximal anastomosis was completed. Care was taken to ensure that the posterior layer of sutures was sound.

If the heart had fibrillated-which was unusualit was defibrillated using a $\mathbf{4 0}$ or 60 watt second D.C. capacitator discharge. Bypass was discontinued and disconnected, and the chest wall was closed over water-seal drainage. Skin-to-skin time for these experiments was 3 hours.

POST-OPERATIVE CARE As with bypass surgery in humans, continued post-operative ventilation, biochemical checking, and observation of the animal were required until it became fully conscious. It received penicillin, one million units, and streptomycin,
1 g., daily for one week after operation. Anticoagulants were not used post-operatively.

\section{RESULTS}

The experiment was successfully completed in three animals on $10 \mathrm{March}, 21 \mathrm{April}$, and $3 \mathrm{May}$ 1967. After one week's post-operative care in the $\vec{\circ}$ Department of Surgery, the animals were returned $\overrightarrow{\vec{\omega}}$ to the University of Otago Farm, where they lived $\stackrel{\omega}{\mathscr{\omega}}$ normally on pasture.

In order to check the transplanted valves macroscopically and microscopically, the animals $\omega$ were killed in the first week of October 1967. Thus i the first valve had been in position seven months, $\omega_{0}$ the second five and a half months, and the third o five months.

On each occasion the necropsy was performed $\vec{z}$ by one of us (J. B.). As soon as the animal was dead, the valves were inspected and photographed $\vec{\bullet}$ in the fresh state, and the specimens were immediately placed in $10 \%$ formalin solution.

MACROSCOPIC FINDINGS Macroscopically there was no evidence of infection. There were no vegetations present on the valve cusps. There was no evidence of contraction of the cusps or fibrosis $\mathscr{Q}$ (Fig. 1a). They appeared thin and pliable but less $\overrightarrow{\overrightarrow{0}}$ translucent than normal (Fig. 1b). The aortic wall, 3 including that portion having cardiac muscle, appeared to be 'totally accepted'. There appeared to be no disintegration of the allograft, nor any evidence of dilatation of that portion comprising cardiac muscle.

MICROSCOPIC FINDINGS Paraffin sections were cut in the longitudinal plane to include the host pulmonary artery distally and the graft and the pulmonary artery proximally. Paired sections were음 stained with haematoxylin and eosin and van $\frac{D}{2}$ Gieson.

The nature and extent of the histological N changes are illustrated diagrammatically in Fig. 2 \% in order that the photomicrographs (Figs 3 to 6) can be more easily related to the whole specimen. $\tilde{\omega}$ The limits of the grafted valve are indicated approximately by sutures near the proximal ando distal margins.

The cusp of the valve (Fig. 3), and also $a \stackrel{\oplus}{+}$ tongue of tissue running from the valve for a short 0 distance between the endocardium and the

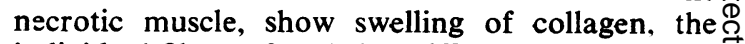
individual fibres often being difficult to distinguish. $\stackrel{\mathbb{Q}}{\mathscr{Q}}$ In this cusp cells are very few in number and pyknotic, although beneath the endocardium this degenerate collagen contains moderate numbers 

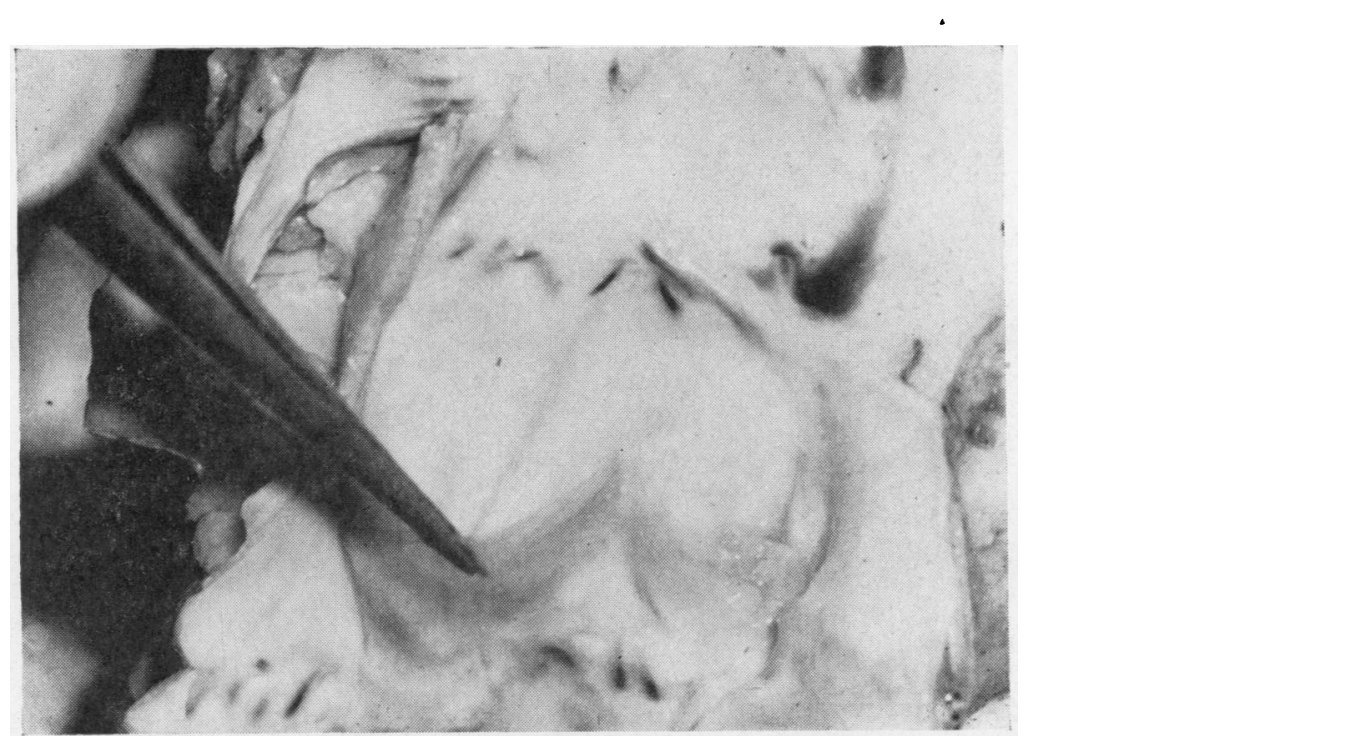

FIG. 1b. View of allograft aortic valve cusp six months after the valve unit (myocardial element cusps and base of aorta) was sutured in continuity into the main pulmonary artery. The cusps show no evidence of fibrosis or contraction. They appear thin and pliable.

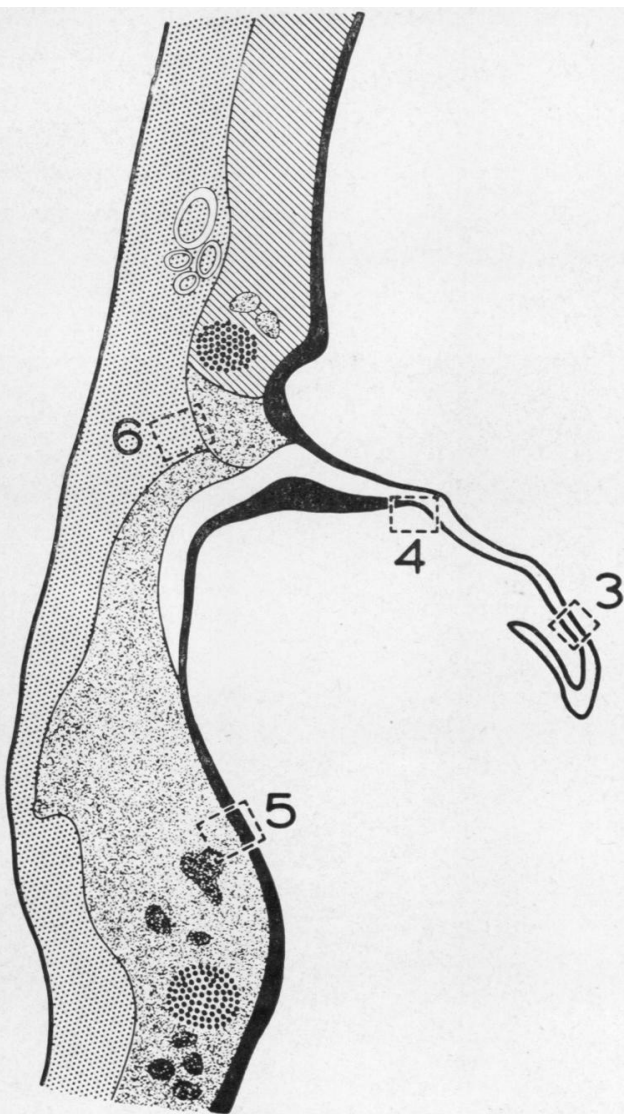

FIG. 2. Diagram of section of allograft valve cut in the longitudinal plane to show the sites of origin of the photomicrographs (Figs 3 to 6). 


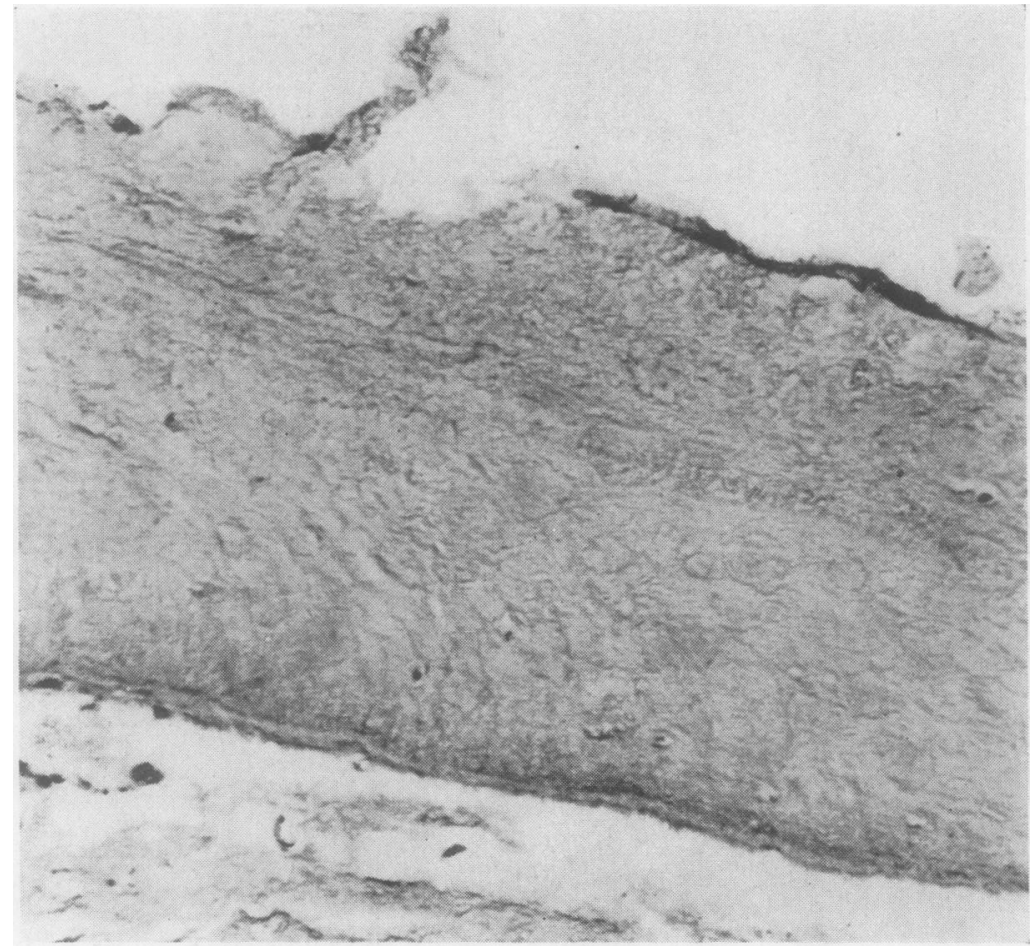

FIG. 3. Hypocellular degenerate valve showing only very occasional pyknotic cells. H.E. $\times 196$.

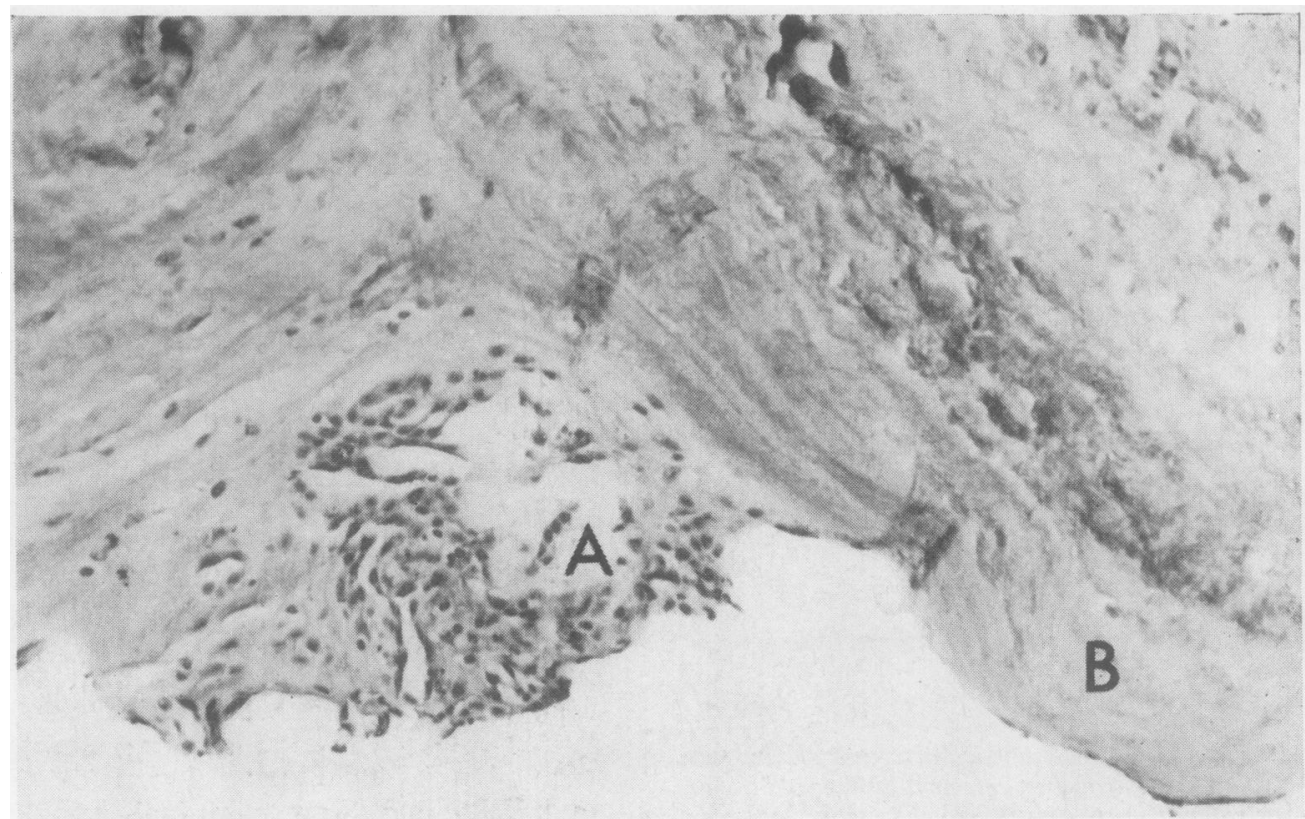

FIG. 4. Fibroblasts in growing tip of advancing endocardium $(A)$ with adjacent degenerate valve $(B)$. H.E. $\times 196$. 
of fibroblasts, with no evidence of proliferative activity.

The endocardium and arterial intima are noticeably thickened near both suture lines and contain increased numbers of fibroblasts lying in loose collagen. The zone of thickened endocardium narrows slightly between the proximal suture line and the valve attachment, where it again increases in width. An island of active fibroblast proliferation near the valvular extremity of the thickened endocardium is illustrated in Figure 4. Similar intimal thickening is seen on the arterial aspect of the valve attachment. Endothelial proliferation on both proximal and distal aspects of the graft extends only a short distance on to the cusp itself, the greater part of which is completely devoid of endothelial covering. (The continuity of the actively growing endocardial and intimal layers with the adjacent host tissues and the absence of endothelial cells from the cusp suggest that these cells are derived from the adjacent normal host tissues and not from cells seeded from the bloodstream. One might expect the latter to give rise to discontinuous islands of endothelium.)

The entire muscular portion of the graft is necrotic, the tissue being refractile, virtually structureless, and devoid of cells except near its outer margins. Several areas of calcification are seen at some distance from the attachment of the valve. Smaller necrotic areas are seen in the elastic tissue at the arterial extremity of the graft (Fig. 5).

A loose layer of fibro-fatty tissue invests the whole of the outer part of the specimen (Fig. 6). This shows some fibroblastic proliferation near the necrotic tissue.

There is also a light to moderate infiltration of lymphocytes, macrophages, and plasma cells, which are slightly more numerous in the vicinity of the cusp attachment than elsewhere in the specimen. This may possibly be related to the greater thickness of the adventitial layer in this site. (It cannot be stated with any certainty that this infiltration represents a homograft reaction. In the first place most of the grafted tissues are dead or degenerate and therefore of doubtful

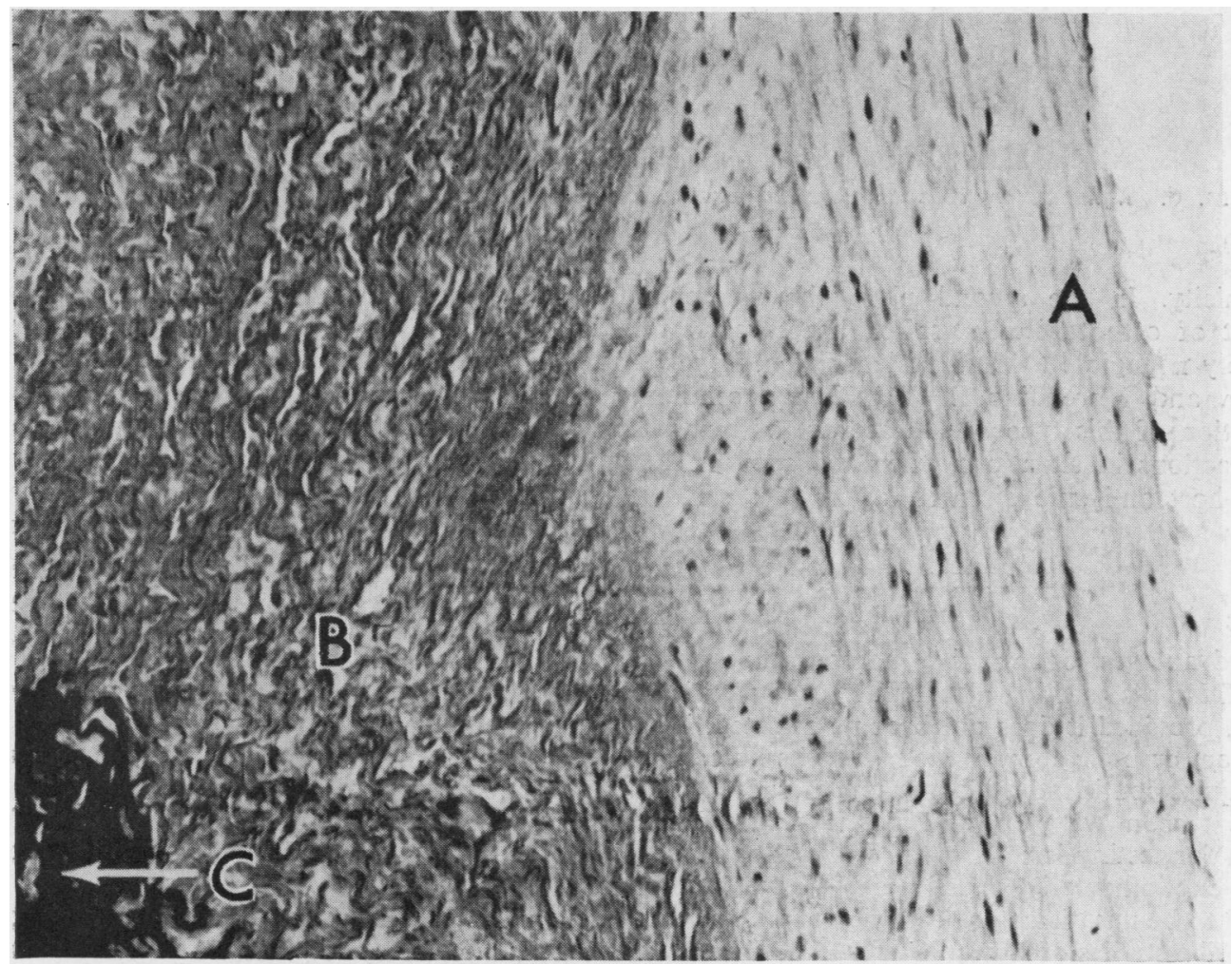

FIG. 5. Thickened endocardium (A) overlying dead muscle $(B)$ which contains a patch of calcification $(C)$. H.E. $\times 196$. 


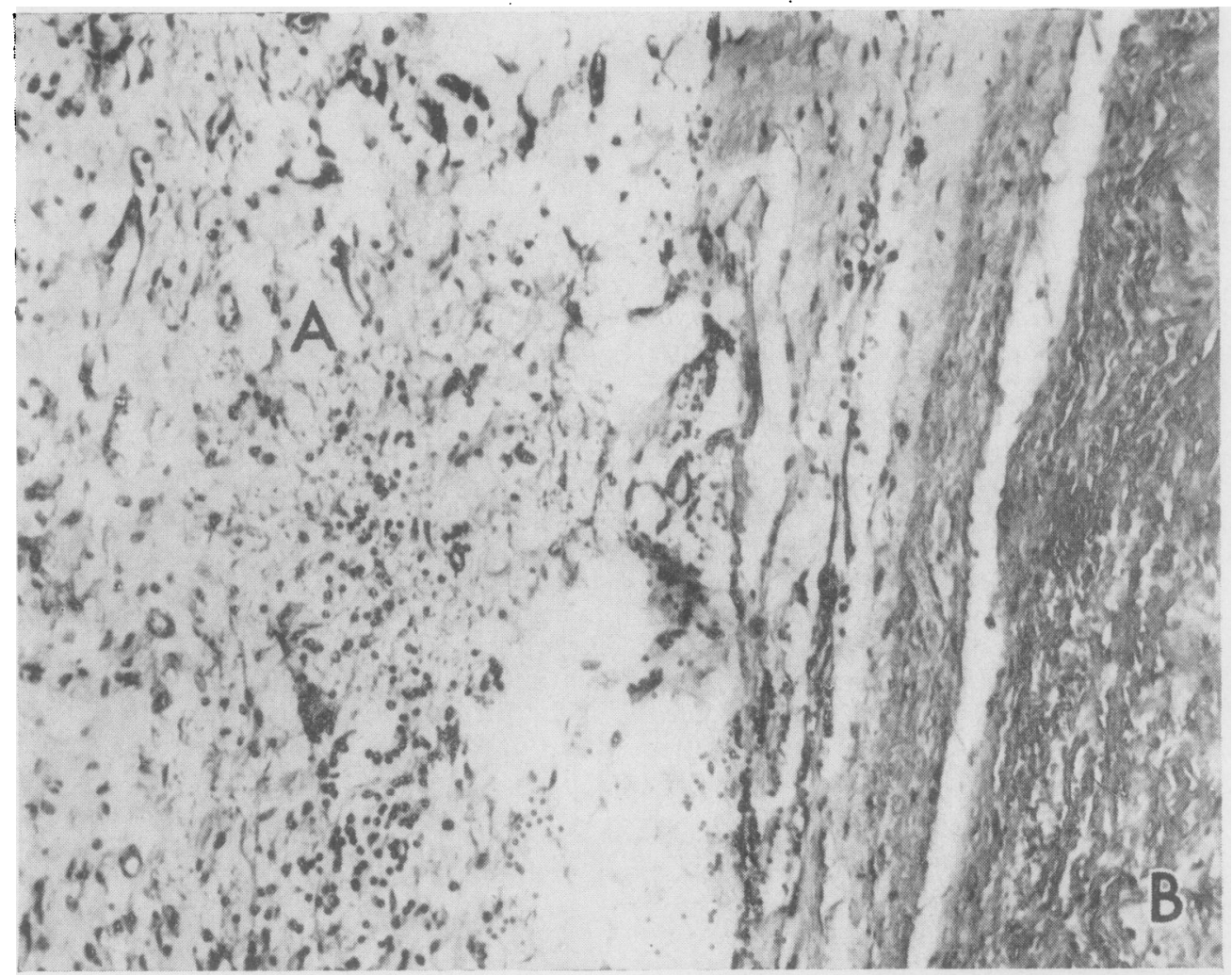

FIG. 6. Inflammatory cells and vascular fibrous tissue (A) adjacent to necrotic muscle (B). H.E. $\times 196$.

antigenicity. In the second place the antigenic content of orthotopically grafted heart valves is probably negligible (Mohri, Reichenbach, Barnes, Nelson, and Merendino, 1967). Finally, cellular infiltration of this type occurs as part of reparative reactions in situations where no question of donor-host antigenic disparity arises.)

\section{DISCUSSION}

The advantages of a valve homograft over a Starr-Edwards plastic valve or any other variant is that, provided it does not become infected, it is free from embolic complications, and its host does not require continued anticoagulant therapy.

The reason why inverted aortic valves were chosen for testing is that mitral valve allograftseither experimentally or clinically-have so far proved to be unsatisfactory (O'Brien and Gerbode, 1964). The studies of Lower, Stofer, and Shumway (1961) suggested that autologous pulmonary valves could be successfully used at mitral level, and
Ross (1967) has confirmed favourable results in clinical practice.

Our experiments were completed before the work of Ionescu, Wooler, Smith, and Grimshaw (1967) was published. These authors reported the use of inverted aortic heterografts in humans as mitral valve substitutes, describing the technique of collecting from pigs, preparing and inserting these grafts into several patients, one of whom died from staphylococcal endocarditis with vegetations covering the cusps of the grafted valve. In the circumstances in which their work was performed their report does not show the microscopic structure of these graft cusps. None the less their work is a significant forward step in the problem of mitral valve replacement. More recently, Ross (1967) has used a similar technique in seven patients, but he has been concerned by the tendency to late failure as reported by Smith (1967). Hence his swing to autologous pulmonary valves.

While these valves may 'work' in their transplanted site in humans, it is important to know 
what is biologically and histologically occurring so that the technique can be accepted with confidence, or rejected.

We therefore submit that much experimental study is still required. Our own study shows (a) that aortic valve allografts can be transplanted as free grafts and sutured into a host pulmonary artery without macroscopic rejection or rupture ; (b) that macroscopically after six months the cusps appeared thin, pliable, and normal; and (c) that microscopically there was necrosis of the muscle in the graft with calcification, but that the graft tissues supporting the cusps developed a protective endothelial sheath. As Dr. Barbara Heslop points out in her report on the slides, the continuity of the actively growing endocardial and intimal layers with the adjacent host tissues and the absence of endothelial cells from the valve suggest that these cells were derived from adjacent normal host tissue and not from cells seeded from the bloodstream.

Although the graft may 'work', one cannot say it is by any means 'accepted'. Rather it remains as an 'inert' matrix in which the muscle becomes necrotic, undergoes calcification, and has a surrounding reparative sheath of fibrous connective tissue.

The paper of McKenzie et al. (1966) sets out the morphological feature of experimental semilunar valve allografts used as mitral valve substitutes in greater detail than earlier studies. Specimens that had been in place for 42 days and longer appeared to be well healed at the annulus of the valve. However, in all valves that had been in place for 86 days or more, fibrotic and cartilaginous changes extended from the mitral annulus on to the grafted tissue, producing narrowing of the valve orifice which became more marked up to a year after operation. Further, they described histological changes similar to those encountered in the present study with deposition of fibrin on cusp surfaces, cusp thickening from oedema, necrosis of collagen and infiltration with histiocytes, fibroblasts, and occasional polymorphs, and replacement fibrosis of the cusps.

Our own did not show replacement fibrosis of the valve cusps, nor was infection encountered in our study despite the absence of aseptic precautions when collecting the homograft valves.

The satisfactory appearances of the cusps six months after implantation was pleasing and did not lend support to the concept of Lam, Aram, and Munnell (1952), who felt that, so far as the aorta was concerned, the destruction of the recipient animal's aortic valve, by increasing the functional stimulus, would promote the survival of homograft valves in the descending aorta. In our own experiments, host pulmonary valves were left intact, and certainly the grafted valves were not 'the shrunken, fibrotic specimens recovered in experimental studies in dogs', as described by Willman, Zafiracopoulos, and Hanlon (1961). One could not, however, be so sanguine about necrosis of the cardiac muscle part of the allograft valve.

Earlier workers with valve allotransplants had had disappointing results, and reported thickening of the valve cusps (Bill, Peirce, and Gross, 1950 ; Hufnagel, 1951 ; Litwak, Gadboys, Scott, and Ferrara, 1952 ; Lam et al., 1952 ; Brewin, 1956).

Lower, Stofer, and Shumway (1960) excised the pulmonary valve from each of 10 dogs and replaced it with a fresh allograft taken from a donor dog of comparable size. The nine survivors were studied for periods of up to 10 months. They found that where the pulmonary valve had been transplanted the annulus in all was 'moderately' or 'markedly' stenotic. The cusps were acellular, 'thickened and retracted', and the graft was replaced by fibrous tissue. As a result, right ventricular pressures rose post-operatively to levels of 90 to $120 \mathrm{~mm}$. $\mathrm{Hg}$.

Our own findings did not confirm those of Lower et al. (1960) of stenosis and fibrosis. They had used a fresh pulmonary valve allograft, whereas ours were aortic in origin. In our small experimental experience the presence of the normally functioning pulmonary valve proximal to the allograft did not adversely affect the survival of the allograft aortic valve, as Lam had speculated. Indeed, it was interesting to see their survival at a site where there was no 'environment of functional need'.

We are grateful to Dr. Barbara Heslop, Department of Surgery, University of Otago, for her assessment of the macroscopy and microscopy of the specimens.

We thank Miss Pamela Fraser, Mr. Nelson Redshaw, and Mr. Murray Cockerill for technical assistance, the Pathology Department, University of Otago, for preparation of the microscopic sections, Mr. Donald Weston for photography, Miss Yvonne Joel for the diagram, and Miss Noeleen Richardson for secretarial services.

\section{REFERENCES}

Barratt-Boyes, B. G. (1964). Homograft aortic valve replacement in aortic incompetence and stenosis. Thorax, 19, 131.

Beall, A. C. (1961). In discussion of paper by Willman, V. L., Zafiracopoulos, $P$., and Hanlon, C. R. Replacement of the mitral valve with homograft aortic valve. In Prosthetic Valves for Cardiac Surgery. Ed. Merendino, K. A., p. 148. Thomas, Springfield, Illinois. 
Beall, A. C., Jr., Morris, G. C., Jr., Cooley, D. A., and De Bakey, M. E. (1961). Homotransplantation of the aortic valve. J. thorac. cardiovasc. Surg., 42, 497.

Bill, A. H., Peirce, E. C., and Gross, R. E. (1950). Experimental production of an extracardiac shunt around the mitral valve. Arch. Surg., 60, 1114.

Borrie, J., and Mitchell, R. M. (1960). The sheep as an experimental animal in surgical science. Brit. $J$. Surg., 47, 435.

_- Lichter, I., and Miller, W. N. (1967). Experimental heart surgery in sheep: alternating- and direct-current defibrillation. $J$. surg. Res., 7, 560.

Brewin, E. G. (1956). The use of tissue transplants in the surgery of cardiac valvular disease: an experimental study. Guy's Hosp. Rep., $105,328$.

Heimbecker, R. O. (1961). In discussion of paper by Willman, V. L., Zafiracopoulos, P., and Hanlon, C. R. Replacement of the mitral valve with homograft aortic valve. In Prosthetic Valves for Cardiac Surgery. Ed. Merendino, K. A., p. 157. Thomas, Springfield, Illinois.

Hubka, M., Siska, K., and Holec, V. (1967). Replacement of the mitral valve with an aortic valve homograft implanted into the left atrium. J. thorac. cardiovasc. Surg., 53, 260.

Hudson, R. E. B. (1966). Pathology of the human aortic valve homograft. Brit. Heart J., 28, 291.

Hufnagel, C. A. (1951). Aortic plastic valvular prosthesis. Bull. Georgetown Univ. med. Cent., 4, 128.

Ionescu, M. I., Wooler, G. H., Smith, D. R., and Grimshaw, V. A. (1967). Mitral valve replacement with aortic heterografts in humans. Thorax, 22, 305 .

Lam, C. R., Aram, H. H., and Munnell, E. R. (1952). An experimental study of aortic valve homografts. Surg. Gynec. Obstet., 94, 129.
Litwak, R. S., Gadboys, H. L., Scott, G. B., and Ferrara, J. F. (1952). Surgical approach for stenotic lesions of the semilunar valves by excision and cusp replacement under direct vision. J. thorac. Surg., 24, 165.

Lower, R. R., Stofer, R. C., and Shumway, N. E. (1960). A study of pulmonary valve autotransplantation. Surgery, 48, 1090. (1961). Total excision of the mitral valve and replacement with the autologous pulmonic valve. J. thorac. cardiovasc. Surg., 42, 696.

McKenzie, M. B., Titus, J. L., Rastelli, G. C., Pappas, G., and Ellis, F. H. (1966). Replacement of the canine mitral valve with semilunar valves. Ibid., 51, 168.

Mohri, H., Reichenbach, D. D., Barnes, R. W., Nelson, R. J., and Merendino, K. A. (1967). Studies of antigenicity of the homologous aortic valve. Ibid., 54, 564.

Murray, G. (1956). Homologous aortic-valve-segment transplants as surgical treatment for aortic and mitral insufficiency. Angiology, $7,466$.

O'Brien, M. F., and Gerbode, F. (1964). Homotransplantation of the mitral valve. Preliminary experimental report and review of literature. Aust. N.Z. J. Surg., 34, 81.

Ross, D. (1964). Homotransplantation of the aortic valve in the subcoronary position. J. thorac. cardiovasc. Surg., 47, 713.

- (1967). Replacement of aortic and mitral valves with a pulmonary autograft. Lancet, $2,956$.

Smith, J. C. (1967). The pathology of human aortic valve homografts. Thorax, 22, 114.

Willman, V. L., Zafiracopoulos, P., and Hanlon, C. R, (1961), Replacement of the mitral valve with homograft aortic valve. In Prosthetic Valves for Cardiac Surgery. Ed. Merendino, K. A.. p. 142. Thomas, Springfield, Illinois. 